\title{
Application of computer vision and image analysis method in cheese-quality evaluation: a review
}

\author{
Jasmina Lukinac, Marko Jukić, \\ Kristina Mastanjević, Mirela Lučan
}

University of Osijek, Faculty of Food Technology in Osijek, Croatia

Keywords:

Cheese

Quality

Computer

Visual

Evaluation

\section{Article history:}

Received 13.05.2018

Received in revised form 20.06.2018

Accepted 29.06.2018

\section{Corresponding author:}

Marko Jukić

E-mail:

ptfosptfos2@

gmail.com

DOI: $10.24263 / 2304-$

974X-2018-7-2-4

\section{Abstract}

Introduction. This review paper deals with literature analysis of modern computer vision and image analysis methods in cheese-quality evaluation.

Materials and methods. In this paper several cheese types made from cow's milk were analyzed: soft, semihard, and hard cheese. All images shown in this paper were scanned with a flatbed scanner, and then processed using Image J software.

Results and discussion. Because with the most part of the external quality attributes evaluation is timeconsuming, due to visual inspection, computer vision provides a means to perform this task automatically. To evaluate various cheese external quality properties (color), and defects (mechanical openings - gas holes; rind defect - formation of calcium lactate crystals and excessive rind halo; amount and distribution of added ingredients; meltability and oiling-off) computer vision system has been successfully applied. Image analysis was used for measurement of the normal amount of gas production, and abnormal shape or distribution of eyes throughout the structure of Emmental and Tilsit cheese. Image analysis was used to determine the presence of rind halo cheese defect and to measure the area occupied by calcium lactate crystals on surfaces of naturally smoked Cheddar cheese samples. To improve empirical methods (Arnott and the Schreiber test) and to offer a new approach for evaluation of meltability and oiling-off of Mozzarella cheese, computer vision and image analysis method was applied. In addition, digital image analysis is used for evaluation of the addition of some ingredients and evaluation of the amount and distribution of added ingredients into the semi-cooked cheese with added paprika and herbs.

Conclusion. Computer vision and digital image analysis represents an efficient and non-invasive technique able to investigate the cheese optical properties and give information concerning their composition and structure. 


\section{Introduction}

Trained human inspectors usually perform food-quality inspection. This method is highly variable and decisions are not always consistent between inspectors from day to day. Because instruments reduce variations among individuals and are more precise, instrumental measurements are preferred over human inspectors. Instruments can be designed to imitate human testing methods or may be statistically related to human perceptions and judgments to predict quality categories. Researchers have been working to find techniques for evaluating the external and internal quality attributes of agricultural and food products non-destructively [1-5]. Size, shape, and color of food are considered as external quality attributes. Internal quality attributes are texture (firmness, hardness, crispness, tenderness, and juiciness), proximate composition, and nutritive value (carbohydrates, proteins, and vitamins) and defects like pest infestation, internal cavity, frost damage, rotten, etc. While external quality attributes are evaluated by visual judgment, internal quality attributes are difficult to access by visual appearance and there is a need for technology that can determine them. In order to perform objective and reliable food inspection methods suited for routine inspection and quality assurance tasks, the application of non-destructive optical devices is considered ideal [4, 6-11]. Non-destructive optical techniques include computer vision systems (CVS) with online digital cameras/scanners, light and confocal laser scanning microscopes (CLS), the near-infrared (NIR) imaging systems, spectroscopy and hyperspectral imaging systems (HIS), X-ray imaging and ultrasonic devices [1-14]. Over the past few decades, CVS, including traditional CVS, hyperspectral CVS, and multispectral CVS, has been widely used in the food industry for the automatic external quality inspection of food and agricultural products [12-15]. The aim of this paper is to give a comprehensive overview on the principles and applications of computer vision method and image analysis to the assessment of visual parameters in the quality evaluation of cheese, which correlates with quality and safety characteristics. Computer vision method was used routinely in the quality assessment of several dairy products like whey, desiccated milk, yoghurt, and cheese [19-31]. CVS with image analysis are being developed to assess the appearance criteria of cheese, such as color, shreddability, gas holes and mechanical openings, and oiling-off [26-27, 29-30, 32-34]. Furthermore, CVS can be applied in the quality evaluation of cheese during cooking for the determination of browning and melting properties [35], as well as for prediction of shelf life and the determination of color changes during storage with the use of computer vision and artificial neural network (ANN) $[24,29]$.

\section{Materials and methods}

\section{Materials}

In this paper, several cheese types made from cow's milk were analyzed: Mozzarella (soft cheese), Emmental (hard, cooked pressed cheese, Swiss-type cheese,), Cheddar (semihard, uncooked pressed cheese) and Tilsit (semi-hard smear-ripened cheese) and semicooked cheese with added paprika and herbs respectively.

\section{Method}

Literature referenced in this review article was obtained from bibliographic information in Google Scholar, Web of Science, ScienceDirect, Scopus, SpringerLink, 
EBSCO host, Wiley online library, PubMed, DOAB (directory of open acces books), OvidSP database and CAB abstracts.

Getting of the figures. All images shown in this paper are the result of unpublished research of authors of this review paper. Cheese samples were scanned with a flatbed scanner EPSON Perfection V500 Photo (Epson America Inc., USA), and images were processed using ImageJ $1.48 \mathrm{v}$ software (Wayne Rasband, National Institute of Health, Maryland, USA). To avoid external light conditions, scanner was placed in black box and samples were illuminated with scanner bottom LED light (ReadyScan LED). Scanned 24bit images of 300 dpi with dynamic range 3.4 were digitalized and stored in TIFF format.

\section{Results and discussion}

\section{Computer vision - basics}

Computer vision system (CVS) is an engineering technology that combines mechanics, optical instrumentation, electromagnetic sensing, digital video, and image processing technology [36], or a shortly integrated mechanical-optical-electronic-software system. CVS provides suitably rapid, economic, consistent, and objective assessment for the food and agricultural industry. CVS is a non-contact and non-destructive optical technique suitable for online inspection, quality evaluation of food products, and for ensuring the safety and reliability of the product [28]. Food appearance is detected instrumentally by measuring electromagnetic, usually optical, properties. According to the sensor by which images can be generated, optical techniques can be divided in spectroscopy and image analysis methods. Computer vision includes several operations: capturing, processing, and image analysis. Images are formed when light (in the visible spectrum) falls on a partially reflective and partially absorptive object surface, with the scattered photons being gathered up in the camera lens (which is a light collector) and converts to electrical signals by image sensor [37]. After image capturing, the process of converting images into numerical form is called digitization [38-39]. In digitization, the image is divided into a two-dimensional grid of small regions containing picture elements defined as pixels by using a frame grabber (digitizer) and stored in the form of matrices. As a technique, CVS is able to measure the external features of products, to recognize objects and extract quantitative information from digital images [40]. Currently, the main application of CVS occurs in automated inspection and measurement, allowing manufacturers to keep control of product quality. Configuration of CVS is relatively standard; basic components are illumination device (lights), a device for image acquisition (digital camera/scanner), a frame grabber (in the case of an analogue camera), and computer hardware and software (algorithms for image analyzing and preprocessing) to provide disk storage of images and computational capability [26,41].

The illumination device is used for object illumination under test. There are many properties of illumination (light angle of incidence, light source color, direct/diffuse light technique), which must be selected in such a way that a perfectly evaluable image is generated in combination with the material properties of the object under inspection $[37,39,41]$. Image analysis can be easier with good illumination by reducing noise, shadow, reflection, and enhancing image contrast. Factors that influence the choosing of suitable illumination are object geometry under inspection (flat or curved), nature of object surface (absorbing, transmissive or reflective), and the nature of the object feature (opaque, semitransparent or translucent) to be imaged in comparison with the background (backlighting is usually used for detecting objects that are translucent) $[38,43]$. Light at different 
wavelengths carries different levels of energy; all possible wavelengths we call the electromagnetic spectrum. The electromagnetic spectrum consists partly of a visible and nonvisible range [37]. According to the operating range of the spectrum, we distinguish different type of cameras: CCD camera (400-700 nm), near-infrared (NIR) camera (900$1700 \mathrm{~nm}$ ), near ultraviolet (UV) camera $(300-369 \mathrm{~nm})$. Cameras that operate in the visible part of the spectrum are analog and digital cameras. Digital cameras can be equipped with a CCD (charged coupled device) or CMOS (Complementary metal-oxide-semiconductor) sensor arrays [44]. In an analog camera, first the images are recorded, transformed into the analog signal, and then transferred to a digital data-stream in the computer with a frame grabber. In digital cameras, a frame grabber is not needed because the analog signal is sent directly to the computer via a USB or FireWire adapter [45]. Furthermore, the employment of 3-dimensional cameras may help to improve analysis, provide more information and allow the study of complex or irregular-shaped materials with fewer errors and less time [46]. Scanners are usually used for specialized tasks and specific use (extreme resolution, large numbers of output channels or extreme wavelengths). Flatbed scanners are devices that optically scan images and convert it to a digital image. It is a promising analytical instrument suitable for measurements of the colorimetric parameters of colored objects. Flatbed scanning is fast, easy to use, cheap, robust, independent of external light conditions, and with good accuracy. The scanner head (includes mirrors, lens, filter, and CCD array) move over the sample line by line, by a belt attached to a steep motor. Qualifying specification parameters for a scanner are bit (color) depth, resolution, and dynamic range. The higher the scanner's bit-depth, the more accurately it can describe what it sees when it looks at a given pixel. Resolution relates to the fineness of detail that a scanner can achieve and is usually measured in dots per inch (dpi) [47].

The computer hardware and software, which imitates the human brain, is another key component of the computer vision system. Hardware includes a personal computer and color monitor. The personal computer provides disk storage for images and computational capability with vendor-supplied software and specific application programs. A highresolution color monitor enables the visualization of captured images and the effects of various image analysis $[17,28,41,48]$.

\section{Image processing and analysis}

Image processing involves a series of image operations that enhance the quality of an image in order to remove defects such as geometric distortion, improper focus, repetitive noise, non-uniform lighting and camera motion. Image analysis is the process of discriminating the objects (regions of interest) from the background and producing quantitative information, which is used in the subsequent control systems for making decisions. Image processing and analysis steps can be divided into three levels: low, intermediate, and high $[28,36]$. Low-level processing includes image acquisition and preprocessing. Image acquisition encompasses images capturing, with a digital camera, and digitization with a frame grabber (if an analog camera is used). The pre-processing purpose is to improve image quality. The pre-processed image is enhanced in terms of the correction of geometric distortions, the removal of noise, grey level correction, and correction for blurring. Intermediate-level processing involves image segmentation, representation, and description. Image segmentation can be achieved by threshold, edge-based, and regionbased segmentation [28]. The main aim is to divide an image into regions that have a strong correlation with objects of interest. High-level processing involves recognition and interpretation, using statistical classifiers or multilayer neural networks of the region of 
interest. Neural network and fuzzy logic operations have been implemented successfully with computer vision in the food industry [49].

The core technique in computer vision is always related to image processing and analysis. The primary types of object measurements (size, shape, color, and texture) can be acquired from any images [50-51]. In computers, images are stored and processed in the form of matrices whose elements are pixels. Two types of information are stored in pixels; geometry information (location of pixels in the image) and surface information (intensity values associated with pixels). From the geometry information, the size and shape of the object can be obtained. Color and texture can be extracted from the object surface information.

\section{CVS and color determination}

Instrumentally, color measurement can be carried out using conventional or digital (CVS and image analysis) instruments. Instruments for the conventional color measurement are colorimeters, spectrophotometers, and spectroradiometers [52]. Commonly-used colorimeters are Minolta Chromameter, Hunter Lab colorimeter, and Dr. Lange colorimeters [53], which measure color only over a very few square millimeters, and thus their measurements are not very representative in heterogeneous materials such as most food items [53]. Because of this, the need for developing an automatic pixel-based color measurement process, using computer vision, increased. CVS has been used to objectively measure the color of different foods, analyzing each pixel of the entire surface of the food even when it is of non-uniform shape and color [53-54]. The CVS technique works by acquiring the image of an object, analyzing the image to extract the desired image attributes (color data) and presenting them numerically in a particular color space [55]. Colorimetry is used to explain how colors can be measured and specified in a scientific way. Color may be expressed in subjective (responses of the observer) and objective (measured by instruments) attributes. There are three psychological attributes for color description: hue, lightness, and chromaticity. Hue (h) is a color appearance parameter to which colors are described as red, green, blue, and yellow. Lightness $\left(L^{*}\right)$ is a parameter for color brightness by which we can distinguish light and dark color. Chromaticity $\left(C^{*}\right)$ or colorfulness describes the color sensation; when color is fully saturated, the color is considered in its purest version. Color measurement instruments transform or filter reflected spectra to produce reproducible color space coordinates, like $L^{*}, a^{*}, b^{*}, \mathrm{R}, \mathrm{G}, \mathrm{B}, \mathrm{h}, C^{*}, \mathrm{~V}$ [56-59]. Color can be numerically represented by numerous color spaces. Generally, there are three types of color spaces, namely hardware-orientated space, human-orientated space, and instrumental space [60]. Hardware-orientated spaces are used in hardware processing, such as capturing, storing, and displaying (e.g. RGB and CMYK spaces). These color spaces can sense even a very small variation in color and are, therefore, popular in evaluating color changes of food products during processing [61]. RGB (red, green, blue) space is the most popular hardware-orientated space [52], in which color is defined by coordinates on three axes. Human-orientated spaces are linear with regard to the visual perception of human eyes and include HSI (hue, saturation, and intensity), HSV (hue, saturation, value) and HSL (hue, saturation, and lightness). They are not sensitive to a small amount of color variation, and not suitable for evaluating changes of product color during processing. Instrumental spaces are used for color instruments, such as the colorimeter and colorimetric spectrophotometer [62]. Instrumental spaces are CIELab, and CIELu*v*, and CIEXYZ spaces. The CIELab color space is an international standard for color measurements and the most used one due to the uniform distribution of colors that is close to the human perception of color $[35,63]$. 


\section{- Food Technology -}

Euclidean distance between two different colors corresponds approximately to the color difference perceived by the human eye [53].

\section{Applications of computer vision method for cheese-quality evaluation}

With numerous types of cheese and foods containing cheese available on the market, the necessity for the evaluation of cheese-quality properties continues to grow. Consumers' first impression of the cheese quality and desirability of the food is from its appearance. As a highly-versatile dairy ingredient, cheese can be used directly (unheated cheese) or indirectly (cooked cheese). Direct use is as table, sliced or shredded cheese and indirect use is in the form of cheese ingredients in numerous food products. Generally, cheese-quality characteristics can be observed as appearance attributes of unheated cheese at surface and appearance attributes of cooked cheese at the surface. Appearance attributes of unheated cheese are surface uniformity and smoothness, dimensions of shreds, extent of sticking and balling of shreds, size and uniformity of crumbled cheese pieces, level of curd fines, sharpness and uniformity of appearance of cut edges and corners of portions, degree of bending, drying or cracking of exposed slices, and the opacity or translucence. Cheese used as an ingredient in cooking applications attains a temperature of approximately $80-100^{\circ} \mathrm{C}$. Although the appearance attributes of cooked cheese include visual uniformity, gloss, opacity/translucence, color, oiling-off, flow/surface coverage, shred identity, browning, crusting or burning, a key aspect of the cooking performance of cheese is the heat-induced functionality, which is a composite of different attributes, including softening (melting), stretchability, flowability, apparent viscosity, and tendency to brown. Examples of cheesecooking applications are grilled cheese sandwiches, pizza pie, cheeseburgers, pasta dishes and sauces. Cheese-quality attributes can be grouped into microbial, chemical, physical, and functional categories. Attributes of interest for CVS are mostly physical, sensory, and cooking. According to Peri [64], cheese quality may be defined as the degree of acceptability of the product to the end user. Quality criteria involves different types of characteristics, including:

- $\quad$ sensory (taste, aroma, texture, and appearance);

- $\quad$ physical (sliceability, crumbliness, hardness, springiness, mouth-feel);

- cooking (extent of flow, stringiness, browning);

- compositional/nutritional (contents of protein, fat, calcium, lactose, sodium);

- $\quad$ chemical (intact casein, free fatty acids, free amino acids);

- safety (absence of pathogens, toxic residues, foreign bodies and conformity to approved levels of substances such as biogenic amines).

\section{Cheese color}

Color is an indicator of food freshness, ripeness, desirability, and safety [58,65-66]. Thus, color is an important sensory attribute of dairy products. Many factors can affect the color of dairy products like the composition of milk, food additives, manufacturing technology, natural milk microflora activity, maturation techniques during manufacturing, etc. The measurement of color allows for the detection of certain anomalies or defects that food items may present [53]. Color measurements are mainly carried out in two ways: sensory visual evaluation and instrumental analysis [67]. Increased requirements for quality by consumers require the color evaluation of food products to be more rapid, objective, and quantifiable. Sensory visual evaluation is laborious, time-consuming, costly, and tedious. For these reasons, it is recommendable to determine color using color-measuring 
instrumentation [53]. The color of cheese ranges from white to orange. A color measurement is used routinely in quality control and product development to assess the color of curd and cheese. The natural milk microflora activity, the technological processes, and the maturation techniques can change cheese color. Color is related to the diet of a cow, with the addition of coloring and cheese variety. Recent studies also highlight the potential role of colorimetry in assessing the ripening of smear-ripened cheese $[69,68]$ and for measuring defects, such as browning, during cheese maturation [70]. The yellowness of cheese is affected by the presence of carotenoid in the milk, which is dependent on the composition and the type of feed. Research on cheese color as a function of ripening time by Rohm and Jaros [71-72] reported a decrease of $L^{*}$ value and an increase of $a^{*}$ and $b^{*}$ values during the ripening of Emmental cheese. Ginzinger et al. [73] reported that the yellowness index, a one-dimensional measure of cheese color highly correlated with $b^{*}$, increased as cheese aged. Other than traditional color preferences, such as orange Cheddar and white goat's cheese, the most important color parameter is uniformity (no uniform cheese color may signal a manufacturing defect). Buffa et al. [74] investigated the color change of cheese made from raw, pasteurized, and pressure-treated goat's milk. Color was measured using the HunterLab spectrocolorimeter in $L^{*}, a^{*}$ and $b^{*}$ values. Color evaluation demonstrated significant differences between cheeses due to milk treatments and ripening time. The $a^{*}$ value did not show a definite trend throughout ripening, the $L^{*}$ value decreased and the $b^{*}$ value increased as the cheese aged. Contrary to these results, Marchesini et al. [75] reported that crude protein and fat significantly increased through the period of ripening, and led to a significant decrease of the $L^{*}, a^{*}$ and $b^{*}$ values of Asiago cheese color. Through ripening time, there is a high rate of increase in water-soluble nitrogen in a raw milk cheese. Lower moisture and the higher water-soluble nitrogen content could cause an increase of mechanical openings in the cheese surface and the formation of a less homogeneous and less compact protein matrix, resulting in a reduction of lightness values. Food coloring is also added to make certain cheeses appear distinct. For example, the orange color of Cheddar cheese is due to the addition of annatto, a yellow/orange colorant, which is added to achieve a consistent color over seasonal changes [76]. Poltorak et al. [77] measured the color of selected cheeses available in the Polish market with different fat contents, as well as cheeses containing vegetable oil as the milk fat substitute. Color attributes $L^{*}, a^{*}, b^{*}, \mathrm{~h}$ and $C^{*}$ were measured using a chromameter. They observed that the cheeses with reduced milk fat content were significantly lower in $C^{*}$ and $b^{*}$ than the full-fat cheeses. Similarly, $b^{*}$ of cheese made with canola oil, substituting for milk fat, was significantly lower. This was attributed to the fact that the vegetable oils could not markedly affect the intensity of yellow color in cheeses.

\section{Cheese defects}

\section{Mechanical openings (gas/eyeholes; slits)}

Changes in mechanical properties during cheese ripening are major factors contributing to obtaining the desirable openings (eyeholes) instead of slit formation. The eye (gas) holes size, number, distribution, and shape contribute to the typical features of each cheese variety. When the size, number, distribution, and shape of the eyeholes is correct throughout a cheese block, eyeholes are considered as a desirable feature of the Swiss-type cheese (Emmental), Gouda, Ragusano, and Edam cheese. Eye formation due to gas production $\left(\mathrm{CO}_{2}\right.$ and $\left.\mathrm{N}_{2}\right)$ is a major sign of the quality of some types of cheese (Swiss-type 
cheese). Gas holes formed in other cheeses (Tilsit and Havarti) are not called eyes but are typical of these cheeses [78]. In contrast, in other cheese varieties (Cheddar) gas production is considered as a defect [79]. Even in cheeses where eyes or holes are expected and accepted, slits or cracks are formed under certain conditions. The gas holes are normally round shaped and shiny eyes. A good close-knit texture will allow for eye formation and hole growth in Swiss cheese. The negative impact of gas production in cheese can be manifested as an undesirable and atypical appearance and texture with gas holes, and undesirable or atypical aromas and flavors. The negative impact of gas production can be caused by clostridia or excessive $\mathrm{CO}_{2}$ production. Defective eye formation, white spots and a putrid smell in Swiss-type cheese caused by clostridia reported Le Bourhis et al. [80]. Excessive $\mathrm{CO}_{2}$ production in Swiss-type cheese in a later stage of ripening (after warm room) with a formation of oversized eyes and cracks or splits is referred to as late or secondary fermentation [81]. Caccamo et al. [32] investigated the use of image analysis to measure the amount of the surface area of cheese slices occupied by gas holes for Emmental, Ragusano, and Cheddar cheese. Slice thickness of Ragusano and Cheddar was 1 $\mathrm{cm}$, and $1 \mathrm{~mm}$ for Emmental cheese. The aim of image processing was to determine the intensity of the red, green, and blue (RGB) channel of each pixel. The channel that produced the best contrast between holes and areas of the cheese with no holes were applied for further analysis. For the Ragusano and Emmental cheeses, the blue channel was best, while the red channel was best for the Cheddar cheese. Threshold method was used to measure the percentage of the total area occupied by gas holes. Image analysis could be a useful tool for quantitative measurement of the normal amount of gas production, for variation in the amount of gas production across time, and abnormal shape or distribution of eyes throughout the structure of Emmental cheese. Melilli et al. [82] reported the development of early gas defects in a brine-salted pasta-filata Ragusano cheese. In brinesalted cheeses, made from raw milk, early gas formation is typically the result of poor milk quality, poor hygienic conditions during cheese making, slow acid production during cheese making, and slow uptake of salt from brine. Coliform bacteria are a major contributor to early gas production in raw milk cheeses [83], which enter into the cheese from the raw milk and from the environment during cheese making. Because of slow salt uptake by cheese during brining, early gas formation occurs in the form of small numerous holes. Melilli et al. [82] investigated the combined impact of pre-salting the curd before stretching, brine concentration (saturated vs. $18 \%$ salt brine), and brine temperature (12, 15, and $18^{\circ} \mathrm{C}$ ) on coliform count and the development of early gas defects in Ragusano cheese. Results showed a reduction in coliform bacteria in pre-salted Ragusano cheese as a result of a 3-way interaction effect between salt and stretching temperature and curd $\mathrm{pH}$ that significantly reduced the survival of coliform in the cheese.

Some cheeses have a characteristic open texture, with many mechanical openings called slits (Samsoe, Havarti, and blue varieties) [79]. Undesired gas production can result in the appearance of slits, cracks or huffy packages, which are problems in Cheddar cheese [84]. Slits is a term to describe fissures or cracks in the body of the cheese that can be longer than $3.5 \mathrm{~cm}$. The formation of slits has been attributed to a wide variety of causes and interactions (trapped air, refrigerated storage, early and late abnormal gas production). Air entrapped during the compression of curd is thought to be responsible for open texture. The isolated pockets of trapped air form numerous small irregular holes in the cheese (slits). Slit defect can appear during refrigerated storage after the eyes have fully developed and the cheese is moved from the warm room. Early abnormal gas production is typically produced by coliforms, while late gas production is typically caused by Clostridium tyrobutyricum [79,85]. White et al. [86] and Dorge et al. [87] have explored the 
development of slit openings during ripening by nonstarter bacteria. Fox et al., [79] indicate that one of the least-controlled defects in round-eye cheeses is the development of slits that appear during refrigerated storage after cheese is removed from the warm room. Cheddar cheese should not have gas defects. In Cheddar cheese, slit formation is due to gas production from citrate-fermenting lactobacilli. This defect manifests itself at about 90 to $120 \mathrm{~d}$ of aging [79]. There is a high demand for the non-destructive monitoring of eye formation in cheese during and/or after ripening (Figure 1). The image analysis approach was capable of distinguishing slits from areas with no slits and could provide a quantitative estimate of the percentage of area represented by slits. Caccamo et al. [32] developed an image analysis method to analyze the SEM images of cheese microstructure in routine production. Guggisberg et al. [88] used the X-ray CT measurements - as a non-destructive technique - of the cheeses during their ripening for monitoring of eye formation and growth. Schuetz et al., [89] reported computed tomography measurements as a useful and non-destructive tool to monitor the size of individual eyes in cheese and to investigate the overall mechanism of eye formation in cheese. The CT technology distinguishes materials of different density and, therefore, cheese eye volumes can be quantified without destruction of the cheese.

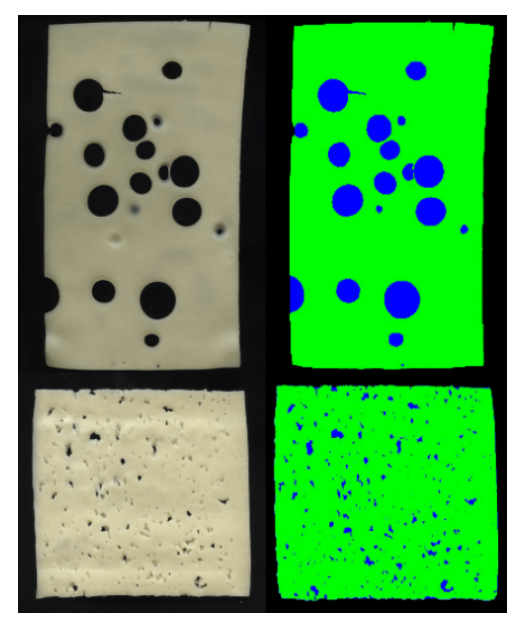

Figure 1. Emmental and Tilsit cheese - images prepared for image analysis of gas holes

\section{Rind defect (formation of calcium lactate crystals and excessive rind halo)}

The formation of calcium lactate crystals has been attributed to the supersaturation of the serum phase of the cheese with calcium and lactate ions, which crystallize and eventually grow into larger aggregates [25,90]. When present on the surface of Cheddar cheese, the calcium lactate crystals form white specks or a haze on the surface of the cheese. Even if they are not harmful, they constitute a significant quality problem for producers of Cheddar, as a microbial problem [91]. Rajbhandari and Kindstedt [25] reported the use of the digital photography and image analysis to measure the area occupied by calcium lactate crystals on surfaces of naturally-smoked Cheddar cheese samples (Figure 2). Results show that image analysis may serve as a useful tool for quantitatively evaluating the effects of factors such as cheese composition, packaging conditions, and 
storage temperature on rate of the crystal growth and time of crystal appearance during storage.

Ripening influences the development of sensory characteristics of cheeses due to its effect on the chemical composition. The problem of abnormal coloring in the rind (black spots, unwanted yellow and orange colorations, and tray marks) may be due to colonization by yeasts, molds or bacterial populations influenced by environmental factors, especially in the airing area and ripening chambers [92-93]. During ripening, cheese loses moisture and the color of the paste becomes darker. Many parameters can cause a dark paste color of cheese, e.g. an excess amount of salt or an inadequate ripening, with high temperatures or excessive air velocity. The presence of an excessive rind halo, an irregular color, and a too dark or too white paste color is one of the main paste color defects. Figure 2 shows the application of image analysis of cheese defect named as excessive rind halo. Zabaleta et al. [94] investigated the sensory quality control of a semi-hard sheep's raw milk cheese variety over five consecutive years (2006-2010) and tried to describe the main sensory defects (eyes, paste color, rind, flavor, texture, and shape) that appear in semi-hard sheep raw milk cheese. One of the investigated cheese defects reported in their paper is an excessive rind halo, described as a too dark or wide paste border. Obtained results showed that mediumand long-ripened cheeses presented a higher percentage of an excess of rind halo with a darker paste color, animal flavor, and marks in the rind.

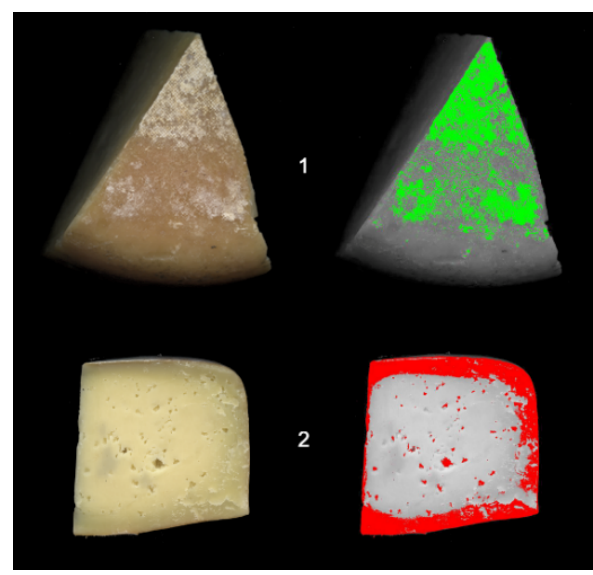

Figure 2. Cheese defects analysis:

1 - Formation of calcium lactate crystals; 2 - Excessive rind halo.

\section{Visual texture}

Image texture analysis is a characterization of visual texture (e.g. rough or smooth), estimated from the digital analysis of an image, enabling information on surface characteristics (shape, dimensions). Image analysis has the potential for analyzing cheese surfaces for features of relevance to quality control, such as roughness, smoothness, shininess, graininess, veins, cracks and slits. Image texture analysis has acquired a wide variety of imaging techniques in the food industry, like online digital cameras or scanners, light and confocal laser scanning microscopes, hyperspectral imaging systems, X-rays, and ultrasonic devices. 


\section{Amount and distribution of added ingredients}

Many cheesemakers add flavor ingredients to cheese. Instead of smoked cheese, they produce cheese with added herbs (e.g. parsley, chives, and garlic) or spices (e.g. chili, cumin, black pepper, dried fruits, lavender or truffles). Digital image analysis can be used for evaluation of the addition of some ingredients (herbs, spices, vegetables, etc.) and evaluation of the amount and distribution of added ingredients into the cheese (Figure 3 ). Pasteurized cheese with vegetable ingredients is one of the new products that may be added to sandwiches, salads, sauce, toast, and pizza. Jelinski et al. [65] used computer vision to determine the distribution and amount of ingredients (garlic, parsley, and pepper) in pasteurized cheese. For localization and extraction of the ingredients, they used a threshold algorithm. An algorithm for image pre-processing was developed in order to extract the area of the edge of the cheese and then to extract the ingredients, using, for that purpose, the quantification of color and localization of the ingredient. It was found that the distribution and amount of ingredients in the samples were determined within a high accuracy when compared with the results of a sensory method. Cheese with garlic and parsley showed $88 \%$ accuracy, and cheese with pepper and parsley showed $81 \%$ accuracy. The results found in this study were promising, and the algorithms developed may be applied in the inspection of different kinds of cheese with ingredients. Different backgrounds were tested, with the black background presenting the best results. It should be highlighted that, for the image acquisition of the analyzed cheese, a scanner was used rather than a camera, the latter being the most usually used equipment in similar studies.

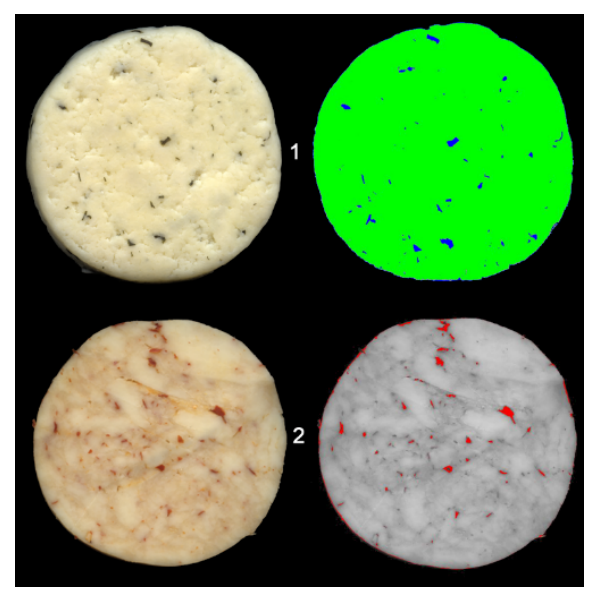

Figure 3. Image analysis of cheese ingredients 1 - herbs; 2 - red paprika.

\section{Shreddability}

Good shreddability is characterized by the free flow of the shredded cheese and a low tendency of the cheese shreds to stick together to form balls or clumps. Cheese with relatively low moisture, high protein, low proteolysis, and a high calcium-to-casein ratio tend to have a better shreddability (Emmental, Gruyere, low-moisture Mozzarella, Gouda, young or medium aged Cheddar and Provolone), than cheeses that have relatively high 
moisture, a high degree of proteolysis, low calcium, and low protein-to-fat ratio (Tetilla and Fontina) [95]. Other factors that are conducive to the clumping of shredded cheese include longer shred length and shred diameter, and free fat content. A computer vision method was used for determining the length of Mozzarella cheese shreds [96]. An image processing algorithm was developed to analyze the image of cheese shreds without manually separating them and to quantify morphological features to characterize the lengths of individual cheese shreds. The developed method was successful in recognizing individual shreds, even when shreds were touching or overlapping [29]. Current shred evaluation methods are manual, which is an extremely time-consuming process. Ni and Gunasekaran [30], for cheese shred length measurements, used a robust and efficient algorithm, the X-Y sweep method. Obtained results showed an accuracy of 99\%, and the X-Y sweep method can work correctly with all the shred-shaped objects. The $\mathrm{X}-\mathrm{Y}$ sweep measurement data can be used to compute certain quality indices to characterize the degree of free-flowing and the degree of matting of the shreds.

\section{Cooking properties}

Process cheese is made by further processing, which involves the blending and shredding of finished natural cheese. Meltability is a major functional property of cheese, especially in the applications of cheese as toppings or ingredients in prepared consumer foods. The CVS method was employed to analyze the characteristics of Cheddar and mozzarella cheeses during cooking and the results showed that the method provided an objective and easy approach for analyzing the functional properties of cheese.

\section{Meltability (Flowability), Browning and blister formation, Oiling-off}

The meltability (flowability) is the extent in dimension to which melted cheese flows and spreads upon heating, expressed as a percentage of the dimension in the unheated sample. The uniform melting quality of processed cheese is considered as a desirable property [97[. The ability to soften on heating is had by most cheeses, e.g. Cheddar, Gouda, Emmental, Mozzarella, Raclete, and Blue cheese. Various tests have been described in the literature to measure flowability: Arnott test, Schreiber test, Price-Olson test [97-102]. The melting quality of cheese is defined as the property of cheese shreds to fuse together upon heating. Several papers reported on the melting properties of Mozzarella cheese. The most popular empirical methods to measure or quantify Mozzarella-melting properties are the Arnott test [97] and the Schreiber test [99-100]. In these tests, a thin disk of cheese is heated at a pressed temperature and duration (Arnott test: $100^{\circ} \mathrm{C}$ for $15 \mathrm{~min}$; Schreiber test: $232^{\circ} \mathrm{C}$ for $5 \mathrm{~min}$ ) and the change in sample height (Arnott test) or diameter (Schreiber test) is measured and used as an index of cheese melting. Melting quality was expressed as a percentage of the dimension in the unheated sample [97-100]. Olson and Price modified the Arnott test to measure the melting behavior of pasteurized processed cheese. A thin disk of cheese (25 mm diameter, $40 \mathrm{~mm}$ height) is placed in the closed end of a glass tube $(30 \mathrm{~mm}$ diameter, $250 \mathrm{~mm}$ height) placed horizontally on a baking sheet in the pre-heated oven (at $180^{\circ} \mathrm{C}$ ) and heated for 15 minutes. At the end, the flow distance was measured with a ruler and expressed in millimeters [102]. Muthukumarappan et al. [99] investigate the effect of the different oven temperatures and different heating surfaces (glass Petri dish, aluminum plate, and stainless steel) on the area of melted cheese. The meltability of Mozzarella 
cheese was measured using a computer-imaging system with a CCD video camera. According to results, all the three surfaces can be used in evaluating the sample meltability at $90^{\circ} \mathrm{C}$. For an index of cheese meltability, authors recommend the measurement of a sample melt spread area, rather than its change in height or diameter. Wang and Sun [2627,33] applied a similar procedure to measure the cheese spread area upon melting. The meltability was calculated as the final area minus the original area of the cheese sample. The attractiveness of a pizza comes from its toppings. Mozzarella is used mainly as a pizza topping, based on its functional properties: meltability and stretchability (ability of heated cheeses to form strings and/or sheets when extended uniaxially). With the aim to determine pizza topping percentage and distribution Sun [28] and Du and Sun [51] developed a computer vision method. In order to determine the topping distribution, they developed a new region-based segmentation technique that can effectively group pixels of the same topping together. The method is based on dividing a pizza image into several equal-area partitions and was developed for measuring topping distribution evenness. Results showed that the new algorithm could reach an average accuracy of $90 \%$ and is capable of processing different types of pizzas. Wang and Sun [33] used CVS to measure the melting properties of Cheddar cheese. Melting property was expressed as the area expansion of the Cheddar cheese slices after cooking. Wang and Sun [26] reported that the melting characteristics of Cheddar and Mozzarella cheese were determined with a computer vision system and compared with those obtained from the Arnott and Schreiber tests. The meltability of Cheddar and Mozzarella cheese, determined with the CVS method, correlated well with the results obtained from the Arnott and Schreiber tests (Figure 4 and Figure 5). They concluded that the CVS method offers a promising new approach in cheese meltability determination. Wang and Sun [26], in their study, reported that the dimensions of cheese slices play an important role in measuring the melting property of cheese, irrespective of cheese variety. This implies the need for standardizing sample dimensions in the measurement of melting characteristics. Employing CVS as an instrument provides a solution for determining the meltability of cheese accurately and reliably. The method is capable of handling specimens in a wide range of sizes, thus, it is more flexible. Everard et al. [103] use a computer vision method to measure the effects of inorganic salt content, moisture/fat ratios and aging on Cheddar cheese meltability.

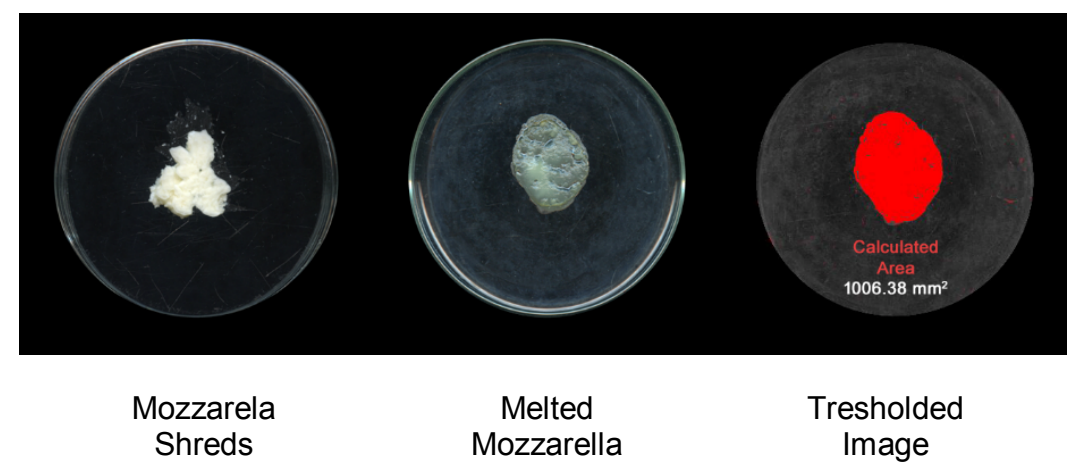

Figure 4. Mozzarella flowability - Schreiber Test 


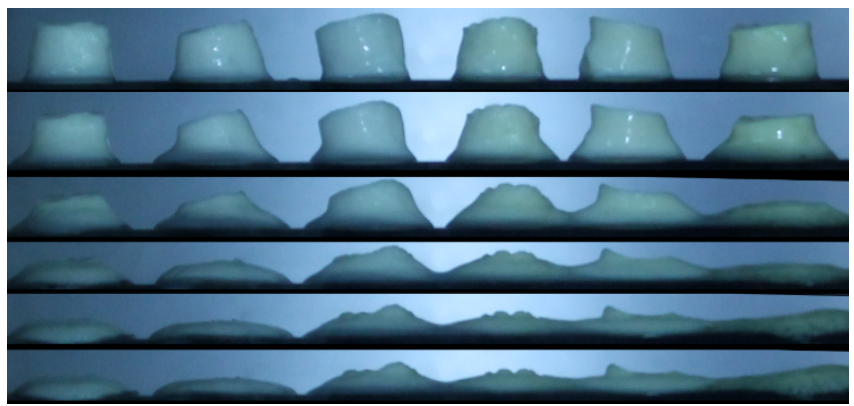

Figure 5. Mozzarella flowability - Arnott Test

\section{Browning and blister formation}

CVS and digital imaging technology have been applied to quantify the pizza-baking properties and performance of different cheeses (Mozzarella, Cheddar, Colby, Edam, Emmental, Gruyere, and Provolone [104], including the browning and blistering [105]. Light-brownish discoloration is observed on the cheese surface after cooking cheese and cheese-containing foods. Browning property is the overall color evaluation of the cheese after pizza baking. Mild browning is acceptable and even desirable, while excessive browning is undesirable [106]. CVS technology has been used successfully to assess the browning of cheese during heating. Compared with conventional methods using colorimeters, the computer vision method is efficient and provides more information on the color change of cheese by making continuous measurements possible. It also has the advantage of handling surfaces with uneven color distributions, such as cooked Mozzarella cheese. Wang and Sun [34] investigated the browning properties of Cheddar and Mozzarella cheeses. Browning results from Maillards reactions of sugars with amino acids at high temperature. This can come from residual lactose or galactose after cheesemaking, or when ingredients such as skim milk powder are added to the hot cheese as part of the cooking/stretching process. Browning can be controlled by varying the content of galactose and amino acid $[34,105]$. Browning can be considered as a defect in processed cheese, or as desirable property when it is used as cheese toppings. The preferred appearance for Mozzarella cheese baked on a pizza is the formation of evenly spread brown blisters over the white/yellow surface of the cheese, rather than a general browning. Blister formation can be evaluated by measuring the size and the shape of cheese blisters on pizza, and browning can be quantified using computer visioning [33-34,104,107]. The blistering and browning of cheese during baking results in a nonhomogeneous color distribution on pizzas. The blister color of pizza cheese can be assessed directly on baked pizza or indirectly by heating the cheese in a boiling water bath [105]. Blister formation occurs during pizza baking. Blisters are trapped pockets of heated air and steam that may be preferentially burned during baking, and blistering has been suggested to be affected by cheese-melt properties. During the heat treatment of a pizza surface, evaporating water and air are trapped between cheese shreds, and collected in bubbles under the melting cheese surface. Steam and air expand. A thin layer of cheese is lifted off the rest of the pizza, initiating the blister formation. The top of the blister becomes thinner during cheese rising. Liquid fat at the surface flows down the sides of the forming blister, moisture is lost from cheese at the top surface of the blister, and the top of the blister turns brown. At other 
locations on the surface of the pizza, the cheese retains its white color because the free oil present there prevents excessive moisture loss from the surface. Mozzarella is the most prone to blister formation, especially when baked on a pizza [104,107-108]. Large blisters are usually less circular than smaller blisters, and cheeses with lower elasticity or stretching resistance can form larger blisters [108]. Cheeses with higher salt content have smaller blisters and this was thought to relate to the softening temperature increasing at higher salt levels.

\section{Oiling-off}

Oiling-off is the tendency of heated cheese to exclude oil. This ability is typical for most rennet curd varieties. The conventional method for oiling-off the properties of cheese determination is with a fat-ring test using filter paper [109], or a quantitative test using centrifuges [110]. A fat-ring test considers placing a cheese disc of specified dimensions on a circular filter paper, heating under defined conditions of time and temperature and cooling. Computer vision method was developed as an effective and efficient method for determining the oiling-off property of cheese (Figure 6). The oiling-off (free oil formation or fat leakage) property of cheese is the separation of liquid fat from the melted cheese body into oil pockets, particularly at the cheese surface.

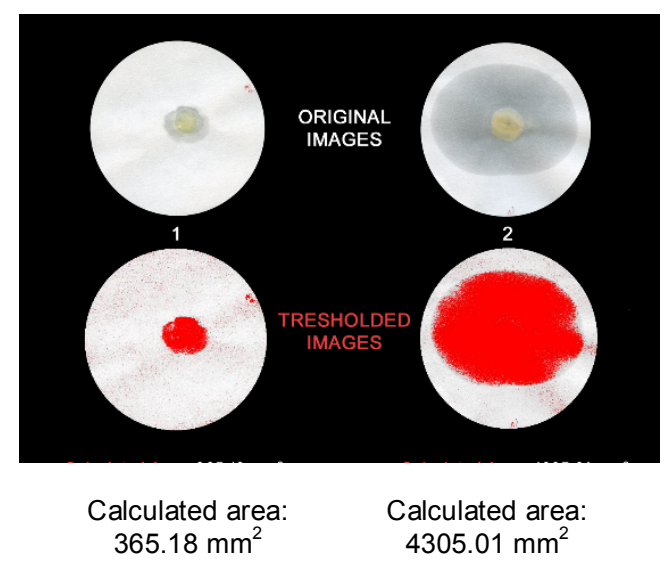

Figure 6. Mozzarella samples with small (1) and large oiling-off effect (2).

Oiling-off property can be considered as a desirable quality when is used as cheese toppings (provides the pizza with a shining appearance) or as an unacceptable defect in processed cheese [110-111]. The moderate release of free oil from cheese during heating is desirable in most cooking applications. Wang and Sun [112-113] studied the oiling-off property of cheese with computer vision. Free oil released on heating was absorbed by the filter paper forming a ring, the diameter of which was indicative of the extent of oiling-off. Wang and Sun [112] investigated the impact of the dimensions (area and thickness) of cheese samples on the oiling-off property of Mozzarella and Cheddar cheese, and a wide range of image features extracted from images of cheese (before and after cooking). Extracted image features were luminance, histogram-related and percentage oil area features. The results showed a temperature-dependent relationship between image 
parameters and fat leakage. The change of percentage oil area upon cooking was in good accordance with the oiling-off property of cheese as observed, presenting a proper description of the oiling-off property of both Cheddar and Mozzarella cheeses. Along with its significant correlation with fat leakage, the percentage oil area was considered as a suitable oiling-off index. Correlation between CVS and traditionally fat-ring tests for evaluation of the oiling-off property of cheese (Cheddar and Mozzarella) was significant, as reported by Wang and Sun [112]. The results showed that it is possible to determine the oiling-off property of cheese with computer-vision image features. For determination of the oiling-off property of cheese, image features were extracted from segmented images. All cheese discs were melted into an uneven area and produced an oil ring around them. The oil area was segmented by a threshold method and their total area was measured with the computer-vision system. Extracted image attributes from images of cheese before and after cooking were luminance features, histogram-related features, and percentage oil area. The histograms of cheese discs were extracted in order to compare the gray-level distribution of cheese pixels before and after cooking. Luminance features were extracted from segmented cheese images on the gray values base. The results showed a good and temperaturedependent correlation between luminance features, percentage oil area, and fat leaking. Therefore, the number and intensity of gray-level pixels are the most promising image feature for the evaluation of the oiling-off properties of cheese, indicating excellent oilingoff representation by careful thresholding and appropriate parameter definition.

\section{Advanced use of computer vision in cheese-quality evaluation}

Curd moisture content in cheese is determined by syneresis of curd. In the cheese industry, syneresis is empirically controlled, and there are no technologies available for the online monitoring of curd syneresis to assist the cheesemaker [114]. Continuous measurement of curd moisture during syneresis is challenging, which limits the precision and accuracy of all reported methods [115-117). Increasing temperature (cooking) of the curd/whey mixture enhances syneresis, which is reflected in a lower moisture content of cheese after pressing. The control of syneresis is important because curd moisture content has an impact on cheese ripening. Computer vision and colorimetric techniques were investigated as a potential means of monitoring the gravimetric measurements of curd and whey during the syneresis phase of cheese manufacture in a stirred-curd context. Computer vision techniques distinguished the effects of $\mathrm{pH}$ and stirring speeds, and it was shown that, with the inclusion of known factors and calibration to a range of operating conditions, there is the potential for predicting a syneresis endpoint. It was found that the accuracy of a computer-vision system for monitoring syneresis improves with size of field of view [22, 103, 114, 118-119]. Syneresis was studied using images captured of the surface of the curd/whey mixture, using five image texture analysis techniques by Fagan et al. [120]. A wide variety of approaches is emerging for image texture analysis, as illustrated by the fact that five different techniques were compared in that study. Mateo et al. [119] reported the comparison of two online optical sensing systems for monitoring syneresis during cheese manufacture, with a digital camera and online visible-near infrared (NIR) sensor. Digital cameras capture spatial information and store images of the curd/whey mixture. The shrinkage of curd pieces is measured using image analysis. An online visible-near infrared (NIR) sensor was used for predicting syneresis indices and it was concluded that this technique was adequately robust to be implemented in the cheese industry to facilitate information about critical steps of production. An online visible-near infrared spectroscopy 
has potential as a useful process analytical tool for better online process control and to provide benefits to the cheese industry. The hyperspectral imaging (HSI) combines conventional spectroscopy and imaging techniques to acquire both spectral and spatial information from an object simultaneously. A typical HSI system consists of a highperformance camera with a large dynamic range, low noise level, good quantum efficiency, an imaging spectrograph, and a stable light source [121]. The result of the measurements with HSI is a three-dimensional data structure or a hyperspectral data cube ('hypercube') in which each pixel of a hyperspectral image can be interpreted as a spectrum [122-124]. Gowen et al. [125] reported on the potential applications of HSI for quality control in dairy foods. HIS technique could be able to detect the presence of starch, incorporated as an adulterant, in fresh cheese [14], quantization of sugar, citric acid, and salicylic acid in different types of cheese, for classification of cheese according to protein, fat, and carbohydrate content [126-127] and detecting water in cheese in an individual sample. The detection of contamination on cheese, in this example a slice of cheese with plastic contamination, was imaged using the NIR HSI system. Gunasekaran and Ding [128] reported the three-dimensional analysis (3-D) of microstructure characteristics of fat globules in Cheddar cheese using confocal laser scanning microscopy (CLSM) and image analysis. 3-D information is important to evaluate accurately microstructural characteristics of cheddar cheese. CLSM as an alternative way to observe food structure with high resolution, without disturbing the internal structure. Image analyses were used to evaluate the number, size and shape characteristics of fat globules in the samples as the process parameters and fat levels may be changed to achieve the required textural qualities. This method enables the in situ 3-D evaluation of fat globule characteristics. Recently, image analysis has been applied for analysis of the SEM images of cheese microstructure [129].

\section{Conclusion}

CVS is primarily a substitute for human vision. Digital image analysis represents an efficient and non-invasive inspection technique able to investigate the food optical properties and, when combined to suitable classification models, to give information concerning their composition and structure. This technique has been successfully applied to the study of the optical properties of various dairy products.

\section{References}

1. Jokic S., Velic D., Bilic M., Lukinac J., Planinic M., Bucic-Kojic A. (2009a), Influence of Process Parameters and Pre-treatments on Quality and Drying Kinetics of Apple Samples, Czech Journal of Food Sciences, 27(3), pp. 171-177.

2. Jokic S., Mujić I., Martinov M., Velic D., Bilic M., Lukinac J. (2009b), Influence of drying procedure on colour and rehydration characteristic of wild asparagus, Czech Journal of Food Sciences, 27(2), pp. 88-94.

3. Jokic S., Mujić I., Bucic-Kojic A., Velic D., Bilic M., Planinic M., Lukinac J. (2014), Influence of extraction type on the total phenolics, total flavonoids and total colour change of extracts in different varieties of figs, Food in health and disease, 3(2), pp. 90-95.

4. Lukinac J., Jokic S., Planinic M., Magdic D., Velic D., Bucic-Kojic A., deBilic M., Tomas S. (2009), An application of image analysis and colorimetric methods on color change of dehydrated asparagus (Asparagus maritimus L.), Agriculturae Conspectus Scientificus, 74(3), pp. 233-237. 
5. Budzaki S., Koceva Komlenic D., Lukinac J., Cacic F., Jukic M., Kozul Z. (2014), Influence of cookies composition on temperature profiles and qualitative parameters during baking, Croatian Journal of Food Science and Technology, 6(2), pp. 72-78.

6. Tao Y., Heinemann P.H., Varghese Z., Morrow C.T., Sommer III H.J. (1995), Machine vision for color inspection of potatoes and apples, Transactions of the ASAE, 38(5), pp. 1555-1561.

7. Pearson T. (1996), Machine vision system for automated detection of stained pistachio nuts, Lebensmittel Wissenschaft und Technologie, 29(3), pp. 203-209.

8. Abduallah M.Z., Abdul-Aziz S., Dos-Mohamed A.M. (2000), Quality inspection of bakery products using colour-based machine vision system, Journal of Food Quality, 23, pp. 39-50.

9. Magdic D., Lukinac J., Jokic S., Cacic-Kenjeric F., deBilic M., Velic D. (2009), Impact analysis of different chemical pre-treatments on colour of apple discs during drying process, Croatian Journal of Food Science and Technology, 1(1), pp. 1-35.

10. Lukinac J., Velic D., Magdic D., Mujić I., deBilic M., Jokic S. (2013), Antibrowning effects of various pretreatment methods on dried apple samples, Acta Horticulturae, 989, pp. 261-270.

11. Lakshmi S., Pandey A.K., Ravi N., Chauhan O.P., Gopalan N., Sharma R.K. (2017), Nondestructive Quality Monitoring of Fresh Fruits and Vegetables, Defence Life Science Journal, 2(2), pp. 103-110.

12. Karoui R., Mazerolles G., Dufour E. (2003), Spectroscopic techniques coupled with chemometric tools for structure and texture determinations in dairy products, International Dairy Journal, 13(8), pp. 607-620.

13. Renu R., Chidanand D.V. (2013), Internal quality classification of agricultural produce using non-destructive image processing technologies (soft X-ray). International Journal of Latest Trends in Engineering and Technology, 2(4), pp. 535-543.

14. Barreto A., Cruz-Tiradoa J.P., Sichea R., Quevedo R. (2018), Determination of starch content in adulterated fresh cheese using hyperspectral imaging, Food Bioscience, 21, pp. 14-19.

15. Park B., Lawrence K.C., Windham W.R., Smith D.P. (2004), Multispectral imaging system for fecal and ingesta detection on poultry carcasses, Journal of Food Process Engineering, 27(5), pp. 311-327.

16. Lu R., Cen H. (2013), Instrumental Assessment of Food Sensory Quality, Woodhead Publishing: Sawston, Cambridge, UK.

17. Zhang B., Huang W., Li J., Zhao C., Fan S., Wu J., Liu C. (2014), Principles, developments and applications of computer vision for external quality inspection of fruits and vegetables, A review, Food Research International, 62, pp. 326-343.

18. El Masry G.M., Nakauchi S. (2016), Image analysis operations applied to hyperspectral images for non-invasive sensing of food quality - A comprehensive review, Biosystems engineering, 142 , pp. 53-82.

19. Vyawahare A., Rao K.J. (2011), Application of computer vision systems in colour evaluation of kunda, a heat desiccated dairy product, International Journal of Food and Dairy Science, 6, pp. 253-266.

20. Vyawahare A., Rao J.K., Pagote C.N. (2013a), Application of computer vision systems in colour evaluation of kalakand (milk sweet) - a heat desiccated dairy product, Research and Reviews, Journal of Food and Dairy Technolog, 1(1), pp. 15-21.

21. Vyawahare A., Rao J.K., Pagote C.N. (2013b), Computer Vision System for Colour Measurement - Fundamentals and Applications in Food Industry, A Review, Research and Reviews, Journal of Food and Dairy Technology, 1(2), pp. 22-31.

22. Everard C.D., O'Callaghan D.J., Fagan C.C., O'Donnell C.P., Castillo M., Payne F.A. (2007a), Computer vision and colour measurement techniques for inline monitoring of cheese curd syneresis, Journal of Dairy Science, 90, pp. 3162-3170.

23. Everard C.D., O'Donnell C.P., O'Callaghan D.J., Sheehan E.M., Delahunty C.M., O'Kennedy B.T., Howard V. (2007b), Prediction of sensory textural properties from rheological analysis for process cheeses varying in emulsifying salt, protein and moisture contents, Journal of the Science of Food and Agriculture, 87, pp.641-650.

24. Sofu A., Ekinci F.Y. (2007), Estimation of storage time of yogurt with artificial neural network modelling, Journal of Dairy Science, 90, pp. 3118-3125. 
25. Rajbhandari P., Kindstedt P.S. (2005), Development and application of image analysis to quantify calcium lactate crystals on the surface of smoked Cheddar cheese, Journal of Dairy Science, 88, pp. 4157-4164.

26. Wang H.-H., Sun D.-W. (2002a), Correlation between cheese meltability determined with a computer vision method and with Arnott and Schreiber, Journal of Food Science, 67(2), pp. 745-749.

27. Wang H.-H., Sun D.-W. (2002b), Melting characteristics of cheese, analysis of the effects of cheese dimensions using image processing techniques, Journal of Food Engineering, 52(3), pp. 279-284.

28. Sun D.-W. (2000), Inspecting pizza topping percentage and distribution by a computer vision method, Journal of Food Engineering, 44, pp. 245-249.

29. Ni H., Gunasekaran S. A. (1998), Computer vision method for determining length of cheese shreds, Artificial Intelligence Review, 12, pp. 27-37.

30. Ni H., Gunasekaran S. (2004), Image processing algorithm for cheese shred evaluation, Journal of Food Engineering, 61, pp. 37-45.

31. Langton M., Hermansson A. (1996), Image analysis of particulate whey protein gels, Food Hydrocolloids, 10(2), pp. 179-191.

32. Caccamo M., Melilli C., Barbano D.M., Portelli G., Marino G., Licitra G. (2004), Measurement of gas holes and mechanical openness in cheese by image analysis, Journal of Dairy Science, 87, pp. 739-748.

33. Wang H.-H., Sun D.-W. (2001), Evaluation of the functional properties of Cheddar cheese using a computer vision method, Journal of Food Engineering, 49, pp. 49-53.

34. Wang H.-H., Sun D.-W. (2003), Assessment of cheese browning affected by baking conditions using computer vision, Journal of Food Engineering, 56(4), pp. 339-345.

35. Yam K.L., Papadakis S. (2004), A simple digital imaging method for measuring and analyzing colour of food surfaces, Journal of Food Engineering, 61, pp. 137-142.

36. Patel K.K., Kar A., Jha S.N., Khan M.A. (2012), Machine vision system, A tool for quality inspection of food and agricultural products, Journal of Food Science and Technology-Mysore, 49(2), pp. 123-141.

37. Moeslund T.B. (2012), Introduction to Video and Image Processing. Building Real System and Applications, Springer-Verlag, London, UK.

38. Abdullah M.Z. (2008), Computer Vision Technology for Food Quality Evaluation, Academic Press, Elsevier, San Diego.

39. Brosnan T., Sun D.-W. (2004), Improving quality inspection of food products by computer vision-a review, Journal of Food Engineering, 61, pp. 3-16.

40. Sun D.-W. (2008), Computer Vision Technology for Food Quality Evaluation, Academic Press, Elsevier, San Diego, California, USA.

41. Davies E.R. (2021), Computer and Machine Vision, Theory, Algorithms, Practicalities, 4th ed., Academic Press, Elsevier, Oxford, UK.

42. Gunasekaran S. (1996), Computer vision technology for food quality assurance, Trends in Food Science \& Technology, 7(8), pp. 245-256.

43. (2018), Machine vision and lighting, available at: $\mathrm{http} / / \mathrm{www}$. machinevisiononline.org/public/articles/archivedetails.cfm?id=1430

44. Waltham N. (2013), Observing Photons in Space, 2nd ed., Springer, New York.

45. Sliwinska M., Wisniewska P., Dymerski T., Namiesnik J., Wardenki W. (2014), Food analysis using artificial senses, Journal of Agriculture and Food Chemistry, 62(7), pp. 1423-1448.

46. Ma J., Sun D.-W., Qu J.-H., Liu D., Pu H., Gao W.-H., Zeng X.-A. (2016), Applications of computer vision for assessing quality of agri-food, A review of recent research advances, Critical Reviews in Food Science and Nutrition, 56(1), pp. 113-127.

47. Batchelor B.G. (2012), Machine Vision Handbook, Springer-Verlag Ltd., London.

48. Sun D.-W. (2004), Computer vision-an objective, rapid and non-contact quality evaluation tool for the food industry, Journal of Food Engineering, 61, pp. 1-2.

49. Ying Y., Jing H., Tao Y., Zhang N. (2003), Detecting stem and shape of pears using fourier transformation and an artificial neural network, Transactions of the ASAE, 46(1), pp. 157-162. 
50. Du C.J., Sun D.-W. (2004a), Recent development in the applications of image processing techniques for food quality evaluation, Trends in Food Science \& Technology, 15, pp. 230-249.

51. Du C.J., Sun D.-W. (2004b), Shape extraction and classification of pizza base using computer vision, Journal of Food Engineering, 64, pp. 489-496.

52. Choudhury A.K.R. (2014), Principles of colour appearance and measurement. Volume 1, Object appearance, colour perception and instrumental measurement, Woodhead Publishing, Elsevier, Cambridge, UK.

53. Leon K., Mery D., Pedreschi F., Leon J. (2006), Color measurement in L*a*b* units from RGB digital images, Food Research International, 39(10), pp. 1084-1091.

54. Yagiz Y., Balaban M.O., Kristinsson H.G., Welt B.A., Marshall M.R. (2009), Comparison of Minolta colorimeter and machine vision system in measuring colour of irradiated Atlantic salmon, Journal of the Science of Food and Agriculture,, 89(4), pp. 728-730.

55. Gumus B., Balaban M.O., Unlusayin M. (2011), Machine vision applications to aquatic foods a review, Turkish Journal of Fisheries and Aquatic Sciences, 11(1), pp. 167-176.

56. Francis F.J. (2005), Engineering Properties of Foods, CRC Press, Taylor and Francis, New York, USA.

57. MacDougall D.B. (2001), Instrumentation and Sensors for the Food Industry, 2nd ed., KressWoodhead Publishing, Cambridge, UK.

58. Abbott J.A. (1999), Quality measurement of fruits and vegetables, Postharvest Biology and Technology, 15, pp. 207-225.

59. Clydesdale F.M., Ahmed E.M. (1978), Colorimetry-methodology and applications, CRC Critical Reviews in Food Science and Nutrition, 10(3), pp. 243-301.

60. Trusell H.J., Saber H.J.E., Vrhel M. (2005), Color image processing. IEEE Signal Processing Magazine, 22(1), pp. 14-22.

61. Lana M.M., Tijskens L.M.M., van Kooten O. (2005), Effects of storage temperature and fruit ripening on firmness of fresh cut tomatoes, Postharvest Biology and Technology, 35(1), pp. 8795.

62. Rossel R.A.V., Minasny B., Roudier P., Mcbratney A.B. (2006), Colour space models for soil science, Geoderma, 133(3-4), pp. 320-337.

63. Segnini S., Dejmek P., Oste R. (1999), A low cost video technique for colour measurement of potato chips, Food Science and Technology-Lebensmittel-Wissenschaft \& Technologie,, 32(4), pp. 216-222.

64. Peri C. (2006), The universe of food quality, Food Quality and Preference, 17, pp. 3-8.

65. Jelinski T., Dub C.J., Sun D.-W., Fornal J. (2007), Inspection of the distribution and amount of ingredients in pasteurized cheese by computer vision, Journal of Food Engineering, 83, pp. 3-9.

66. McCraig T.N. (2002), Extending the use of visible/near-infrared reflectance spectrophotometers to measure colour of food and agricultural products, Food Research International, 35, pp. 731736.

67. Melendez-Martinez A.J., Vicario I.M., Heredia F.J. (2005), Instrumental measurement of orange juice colour, A review, Journal of the Science of Food and Agriculture, 85(6), pp. 894901.

68. Dufosse L., Galaup P., Carlet E., Flamin C., Valla A. (2005), Spectrocolorimetry in the CIEL*a*b* colour space as useful tool for monitoring the ripening process and the quality of PDO red-smear soft cheeses, Food Research International, 38, pp. 919-924.

69. Olson D.W., van Hekken D.L., Tunick M.H., Soryal K.A., Zeng S.S. (2006), Effects of aging on functional properties of caprine milk made into Cheddar- and Colby-like cheeses, Small Ruminant Research, 70, pp. 218-227.

70. Carreira A., Dillinger K., Eliskases-Lechner F., Loureiro V., Ginzinger W., Rohm H. (2002), Influence of selected factors on browning of Camembert cheese, Journal of Dairy Research, 69, pp. 281-292.

71. Rohm H., Jaros D. (1996), Colour of hardcheese-1. Description of colour properties andeffects of maduration, Zeitschrift fur Lebensmittel Untersuchung Forschung, 203, pp. 241-244. 
72. Rohm H., Jaros D. (1997), Colour of hardcheese-2. Factors of influence and relation to compositional parameters, Zeitschrift fur Lebensmittel Untersuchung Forschung, 204, pp. 259264.

73. Ginzinger W., Jaros D., Lavanchy P., Rohm H. (1999), Raw milk flora affects composition and quality of Bergkase-3. Physical and sensory properties and conclusions, Lait, 79, pp. 411-421.

74. Buffa M.N., Trujillo A.J., Pavia M., Guamis B. (2001), Changes in textural, microstructural, and colour characteristics during ripening of cheeses made from raw, pasteurized or high-pressuretreated goats' milk, International Dairy Journal, 11, pp. 927-934.

75. Marchesini G., Balzan S., Segato S., Novelli E. (2009), Andrighetto, I. Colour traits in the evaluation of the ripening period of Asiago cheese, Italian Journal of Animal Science, 8, pp. 412-413.

76. Kang E.J., Campbell R.E., Bastian E., Drake M.A. (2010), Annatto usage and bleaching in dairy foods, Journal of Dairy Science, 93, pp. 3891-3901.

77. Poltorak A., Wyrwisz J., Moczkowska M., Marcinkowska-Lesiak M., Stelmasiak, A., Ulanicka U., Zalewska M., Wierzbicka A., Sun D.-W. (2014), Correlation between instrumental texture and colour quality attributes with sensory analysis of selected cheeses as affected by fat contents, International Journal of Food Science and Technology, 50(4), pp. 999-1008.

78. Polychroniadou A. (2001), Eyes in cheese, a concise review, Milchwissenschaft, 56, pp. 74-77.

79. Fox P.F. (2017), Fundamentals of Cheese Science, 3rd ed., Elsevier, London, UK.

80. Le Bourhis A.G., Dore J., Carlier J.P., Chamba J., Popoff M.R., Tholozan J.L. (2007), Contribution of C. beijerinckii and C. sporogenes in association with C. tyrobutyricum to the butyric fermentation in Emmental type cheese, Internationa Journal of Food Microbiology, 113, pp. $154-163$.

81. Frohlich-Wyder M.T., Bachmann H.P., Casey M. (2002), Interaction between propionibacteria and starter/non-starter lactic acid bacteria in Swiss-type cheeses, Lait, 82, pp. 1-15.

82. Melilli C., Barbano D.M., Caccamo M., Calvo M.A., Schembari G., Licitra G. (2004), Influence of brine concentration, brine temperature, and presalting on early gas defects in raw milk pasta filata cheese, Journal of Dairy Science, 87, pp. 3648-3657.

83. Bintsis T., Papademas P. (2002), Microbiological quality of white-brined cheeses, a review, International Journal of Dairy Technology, 55(3), pp. 113-120.

84. Mullan W.M.A. (2000), Causes and control of early gas production in cheddar cheese, International Journal of Dairy Technology, 53(2), pp. 63-68.

85. Thylin I., Schuisky P., Lindgren S., Gottscha J.C. (1995), Influence of pH and lactic acid concentration on Clostridium tyrobutyricum during continuous growth in a $\mathrm{pH}$-auxostat, Journal of Applied Microbiology, 79, pp. 663-670.

86. WhiteS.R., Broadbent, J.R., Oberg C.J., McMahon D.J. (2003), Effect of Lactobacillus helveticus and Proprionibacterium freudenrichii ssp. shermanii combinations on propensity for split defect in Swiss cheese, Journal of Dairy Science, , 86, pp. 719-727.

87. Dorge T., Carstensen J.M., Frisvad J.C. (2000), Direct identification of pure Penicillium species using image analysis, Journal of Microbiological Methods, 41, pp. 121-133.

88. Guggisberg D., Schuetz P., Winkler H., Amrein R., Jakob E., Frohlich-Wyder M.T., Irmler S., Bisig W., Jerjen I., Plamondon M., Hofmann J., Flisch A., Wechsler D. (2015), Mechanism and control of the eye formation in cheese, International Dairy Journal, 47, pp. 118-127.

89. Schuetz P., Guggisberg D., Frohlich-Wyder M.T., Wechsler D. (2016), Software comparison for the analysis of cheese eyes in X-ray computed tomography, International Dairy Journal, 63, pp. 62-69.

90. Rajbhandari P., Kindstedt P.S. (2008), Characterization of calcium lactate crystals on cheddar cheese by image analysis, Journal of Dairy Science, 91, pp. 2190-2195.

91. Swearingen P.A., Adams D.E., Lensmire T.L. (2004), Factors affecting calcium lactate and liquid expulsion defects in Cheddar cheese, Journal of Dairy Science, 87, pp. 574-582.

92. Amato L., Ritschard J.S., Kurtz O., Arias-Roth E., Lacroix C., Schuppler M., Meile L. (2012), Microbial composition of defect smear-a problem evolving during foil-prepacked storage of red-smear cheeses, International Dairy Journal, 27, pp. 77-85.

93. McSweeney P.L.H. (2007), Cheese problems solved, 4th ed., Woodhead Publ, Cambridge, UK. 
94. Zabaleta L., Albisu M., Ojeda M., Gil P.F., Etaio I., Perez-Elortondo F.J., de Renobales M., Barron L.J.R. (2016), Occurrence of sensory defects in semi-hard ewe's raw milk cheeses, Dairy Science and Technology, 96, pp. 53-65.

95. Guinee T.P., O'Callaghan D.J. (1997), The use of a simple empirical method for objective quantification of the stretchability of cheese on cooked pizza pies, Journal of Food Engineerin, 31(2), pp. 147-161.

96. Apostopoulos C., Marshall R.J. (1994), A quantitative method for determination of shred quality of cheese, Journal of Food Quality, 17, pp. 115-128.

97. Arnott D.R., Morris H.A., Combs W.B. (1957), Effect of certain chemical factors on the melting quality of process cheese, Journal of Dairy Science, 40, pp. 957-963.

98. Altan A., Turhan M., Gunasekaran S. (2005), Comparison of Covered and Uncovered Schreiber Test for Cheese Meltability Evaluation, Journal of Dairy Science, 88(3), pp. 857-861.

99. Muthukumarappan K., Wang Y.-C., Gunasekaran S. (1999a), Modified Schreiber Test for Evaluation of Mozzarella Cheese Meltability, Journal of Dairy Science, 82(6), pp. 1068-1071.

100. Muthukumarappan K., Wang Y.C., Gunasekaran S. (1999b), Estimating softening point of cheeses, Journal of Dairy Science, 82, pp. 2280-2286.

101. Park J., Rosenau J.R., Peleg M. (1984), Comparison of four procedures of cheese meltability evaluation, Journal of Food Science, 49, pp. 1158-1162.

102. Olson N.F., Price W.V. (1958), Amelting test for pasteurized process cheese spreads, Journal of Dairy Science, 41, pp. 999-1000.

103. Everard C.D., O’Donnell C.P., Fagan C.C., Sheehan E.M., Delahunty C.M., O'Callaghan D.J. (2005), Correlation between process cheese meltability determined by sensory analysis, computer vision method and Olson and Price test, International Journal of Food Properties, 8, pp. 267-275.

104. Ma X.X., Balaban M.O., Zhang L., Emanuelsson-Patterson E.A.C., James B. (2014), Quantification of pizza baking properties of different cheeses, and their correlation with cheese functionality, Journal of Food Science, 79, pp.1528-1534.

105. YunJ.J., Barbano, D.M., Bond E.F., Kalab M. (1994), Image analysis method to measure blister size and distribution on pizza. In Proceedings from the 31st Annual Italian and Specialty Cheese Seminar. Madison, Wisconsin, USA, pp. 28-29. September 1994, Burns, D.

106. Matzdorf B., Cuppett S.L., Keeler L., Hutkins R.W. (1994), Browning of Mozzarella cheese during high temperature pizza baking, Journal of Dairy Science, 77(10), pp. 2850-2853.

107. Ma X.X., James B., Balaban M.O., Zhang L., Emanuelsson-Patterson E.A.C. (2013a), Quantifying blistering and browning properties of Mozzarella cheese. Part I, Cheese made with different starter cultures, Food Research International, 54, pp. 912-916.

108. Ma X.X., James B., Balaban M.O., Zhang L., Emanuelsson-Patterson E.A.C. (2013b), Quantifying blistering and browning properties of Mozzarella cheese. Part II, Cheese with different salt and moisture contents, Food Research International, 54, pp. 917-921.

109. Breene W.M., Price W.V., Ernstrom C.A. (1964), Manufacture of pizza cheese without starter, Journal of Dairy Science, 47, pp. 1173-1180.

110. Kindstedt P.S., Rippe J.K. (1990), Rapid quantitative test for free oil (oiling off) in melted Mozzarella cheese, Journal of Dairy Science, 73, pp. 867-873.

111. Rudan M.A., Barbano D.M. (1998), A model of Mozzarella cheese melting and browning during pizza baking, Journal of Dairy Science, 81, pp. 2312-2319.

112. Wang H.-H., Sun D.-W. (2004a), Evaluation of the oiling off property of cheese with computer vision, influence of cooking conditions and sample dimensions, Journal of Food Engineering, 61, pp. 57-66.

113. Wang H.-H., Sun D.-W. (2004b), Evaluation of the oiling off property of cheese with computer vision, Correlation with fat ring test, Journal of Food Engineering, 61(1), pp. 47-55.

114. Mateo M.J., O’Callaghan D.J., Gowen A.A., O’Donnell C.P. (2010a), Evaluation of a vat wallmounted image capture system using image processing techniques to monitor curd moisture during syneresis with temperature treatments, Journal of Food Engineering, 99, pp. 257-262.

115. Daviau C., Pierre A., Famelart M.H., Goudedranche H., Jacob D., Garnier M., Maubois J.L. (2000), Characterisation of whey drainage kinetics during soft cheese manufacture in relation 


\section{- Food Technology -}

with the physicochemical and technological factors, $\mathrm{pH}$ at renneting, casein concentration and ionic strength of milk, Le Lait, 80(4), pp. 417-432.

116. Grundelius A.U., Lodaite K., OstergrenK., Paulsson, M., Dejmek P. (2000), Syneresis of submerged single curd grains and curd rheology, International Dairy Joournal, 10, pp. 489-496.

117. Dejmek P., Walstra P. (2004), Cheese: Chemistry, Physics and Microbiology, 3rd ed., Elsevier, London, UK.

118. Renault C., Gastaldi E., Lagaude A., Cuq J.L., Fuente B.T.D.L. (1997), Mechanism of syneresis in rennet curd without mechanical treatment, Journal of Food Science, 62, pp. 907-910

119. Mateo M.J., O'Callaghan D.J., O’Donnell C.P. (2010b), Comparison between red-green-blue imaging and visible-near infrared reflectance as potential process analytical tools for monitoring syneresis, Journal of Dairy Science, 93, pp. 1882-1889.

120. Fagan C.C., Du C.-J., O’Donnell C.P., Castillo M., Everard C.D., O'Callaghan D.J., Payne F.A. (2008), ,pplication of image texture analysis for online determination of curd moisture and whey solids in a laboratory-scale stirred cheese vat, Journal of Food Science, 73, pp. 250-258.

121. Boldrini B., Kessler W., Rebnera K., Kessler R. (2012), Hyperspectral imaging, a review of best practice, performance and pitfalls for inline and online applications, Journal of Near Infrared Spectroscopy, 20, pp. 438-508.

122. Bernhardt P.A. (1995), Direct reconstruction methods for hyperspectral imaging with rotational spectrotomography, Journal of the Optical Society of America A, 12(9), pp. 1884-1901.

123. Park B., Lawrence K.C., Windham W.R., Buhr R.J. (2002), Hyperspectral imaging for detecting fecal and ingesta contaminants on poultry carcasses, Transactions of the ASABE, 45(6), pp. 2017-2026.

124. Park B., Lawrence K.C., Windham W.R., Smith D.P. (2006), Performance of hyperspectral imaging system for poultry surface fecal contaminant detection, Journal of Food Engineering, 75, pp. 340-348.

125. Gowen A.A., Burger J., O'Callaghan D., O'Donnell C. (2009), 1st International Workshop on Computer Image Analysis in Agriculture, Potsdam, Germany.

126. Burger J., Geladi P. (2006a), Hyperspectral NIR image regression part II, dataset preprocessing diagnostics, Journal Chemometrics, 20, pp. 106-19.

127. Burger J., Geladi P. (2006b), Hyperspectral NIR imaging for calibration and prediction, a comparison between image and spectrometer data for studying organic and biological samples, Analyst, 131, pp. 1152-1160.

128. Gunasekaran S., Ding K. (1999), Three-Dimensional Characteristics of Fat Globules in Cheddar Cheese, Journal of Dairy Science, 82, pp. 1890-1896.

129. Pastorino A.J., Hansen C.L., McMahon D.J. (2003), Effect of salt on the structure-functional relationships of cheese, Journal. of Dairy Science, 86, pp. 60-69. 